\title{
Occupational Exposure to Blood and Body Fluids among Medical Laboratory Science Students of the University of Health and Allied Sciences during Vocational Internship in the Volta Region of Ghana
}

\author{
Philip Apraku Tawiah $\mathbb{D}^{1},{ }^{1}$ Kwabena Oppong, ${ }^{2}$ Emmanuel Sintim Effah, ${ }^{3}$ \\ Albert Abaka-Yawson $\left({ }^{D},{ }^{4}\right.$ and Kingsley Arhin-Wiredu ${ }^{5}$ \\ ${ }^{1}$ Department of Pharmacognosy and Herbal Medicine, School of Pharmacy, University of Health and Allied Sciences, Ho, Ghana \\ ${ }^{2}$ Kumasi Centre for Collaborative Research in Tropical Medicine, Kumasi, Ghana \\ ${ }^{3}$ Mamprobi Polyclinic, Ghana Health Service, Mamprobi, Accra, Ghana \\ ${ }^{4}$ Department of Medical Laboratory Sciences, School of Allied Health Sciences, University of Health and Allied Sciences, \\ Ho, Ghana \\ ${ }^{5}$ Municipal Health Directorate, Ghana Health Service, Sunyani, Ghana \\ Correspondence should be addressed to Philip Apraku Tawiah; ptawiah@uhas.edu.gh
}

Received 2 August 2019; Revised 7 April 2020; Accepted 4 May 2020; Published 1 June 2020

Academic Editor: Christophe Waterlot

Copyright (C) 2020 Philip Apraku Tawiah et al. This is an open access article distributed under the Creative Commons Attribution License, which permits unrestricted use, distribution, and reproduction in any medium, provided the original work is properly cited.

\begin{abstract}
Medical laboratory science students (MLSS), likewise health care workers (HCW), invariably get exposed to blood and body fluids (BBF) of patients. The degree of exposure of these students is even worsened due to their inexperience, which is usually revealed during their vocational training programme. This study therefore determined the prevalence of exposure to BBF and its risk factors among MLSS at the University of Health and Allied Sciences (UHAS). A cross-sectional survey was employed using simple random sampling to enrol 178 students into the study. The study was conducted from February 1 to March 31, 2018, after the annual vocational training programme completed in August 2017. Self-administered questionnaires based on the objectives of the study were given out to participants to complete after their consent was sought. Descriptive data were reported as absolute number with percentages, whereas bivariate and multiple logistic regressions were done to describe relationship between risk factors and exposure to BBF. The study findings revealed that, out of 178 MLSS that participated, 90 (50.6\%) experienced at least one exposure to BBF. Also, work experience before university education increased the chances of exposure to $\mathrm{BBF}(\mathrm{AOR}=7.37,95 \%$ $\mathrm{CI}=1.22-44.43$, pvalue $=0.029)$ compared with those with no experience. In contrast, adequate personal protective equipment $(\mathrm{PPE})$ reduced the tendencies of exposure to $\mathrm{BBF}(\mathrm{AOR}=0.41,95 \% \mathrm{CI}=0.20-0.88, p$ value $=0.023)$ compared with students who had insufficient PPE. The study showed high, 50.6\% (95\% CI: 43.0\%-58.1\%), exposure to BBF. Work history and sufficient PPE were the most significantly associated risk factors. In view of this, there is the need to promote training and education on exposure to BBF particularly among experienced students and also encourage health facilities to continue providing enough PPE for students during their annual obligatory vocational internship programmes.
\end{abstract}

\section{Introduction}

The exposure to BBF among HCW particularly MLSS is an inevitable public health burden that forms part of routine health care delivery and is significant in causing occasional infections and deaths [1]. These health care professionals are at risk of exposure to numerous virulent and deadly microorganisms comprising 26 viruses, 18 bacteria/Rickettsia, 13 parasites, and 3 yeasts that result mostly from exposure to $\mathrm{BBF}$ from patients $[2,3]$. 
Additionally, the exposure to these pathogenic organisms usually results in three significant infections in the health care setting-human immunodeficiency virus (HIV), hepatitis B virus (HBV), and hepatitis C virus (HCV) [3]. Further, a study estimated that in the year 2000, 66,000 hepatitis B, 16,000 hepatitis C, and 200-500 HIV infections were acquired through exposure to BBF through splash of blood, needlestick, and cuts [4]. Unfortunately, among these three important blood-borne infections, only HBV has a vaccine [5].

According to the World Health Organization (WHO) in the year 2010, about 3 million people were at risk of exposure to blood-borne viruses and $90 \%$ of the exposure took place in low- or middle-income countries. Moreover, health care personnel including MLSS in developing countries are at serious risk of blood-transmitted diseases (HIV, HBV and $\mathrm{HCV}$ ) because there is high prevalence in such areas, predominantly sub-Saharan Africa [6]. The Ghana Health Service (GHS) estimated that $30.8 \%$ of all laboratory-confirmed cases of HBV infection (blood-borne disease) were ascribed to the Volta region of Ghana [7], and this happens to be a part of the country where the MLSS of UHAS usually do their annual mandatory vocational internship programmes between the period of June and August.

As predicted in some studies, nurses, medical doctors, and laboratory technicians who are frequently exposed to BBF from patients are of HCW category $[8,9]$. This makes MLSS prone to a higher risk of exposure because of their association with these groups of HCW, and inadequate experience in their line of work during their annual internship programmes also contributes to their risk. Furthermore, needlestick, splashes, cuts, and sharp injuries that expose HCW to blood and other body fluids have been associated with lack of experience in carrying out procedures, insufficient training, work overload, and fatigue $[10,11]$. These experiences are characteristic among students embarking on vocational internship programmes.

Studies on prevalence of occupational exposure to BBF among health care workers and students in both developed $[12,13]$ and developing countries $[14,15]$ have been published. A study carried out among HCW in Serbia revealed that $29.6 \%$ of participants experienced at least one incidence that exposed them to BBF within the previous year [16]. A similar study conducted in Northwest Ethiopia also predicted a higher prevalence of $58.5 \%$ exposure to BBF in their lifetime [17]. A research work carried out among dental students during a period in their clinical course to determine the exposure of $\mathrm{BBF}$ found a high prevalence of $80 \%$, whereas a comparable study carried out among nursing students after a clinical practicum that lasted for six months found $75.6 \%$ of them were exposed to $\operatorname{BBF}[18,19]$. A higher prevalence of $88.6 \%$ was found among nursing students during an internship year that lasted for three months in Assiut City, Egypt [20].

In Ghana, almost all studies published on exposure to BBF focused on HCW. A recent study among health personnel in a district hospital revealed that $67.5 \%$ of them were exposed to BBF in the last 12 months [21]. On the contrary, not many studies have been done among health care students, specifically none among MLSS. In view of this, the study determined the prevalence of exposure to BBF and its associated risk factors among MLSS embarking on vocational internship programmes in the Volta region of Ghana.

\section{Materials and Methods}

2.1. Study Design. A cross-sectional survey was employed using simple random sampling to recruit 178 MLSS in the UHAS into the study. The research work was conducted from February 1 to March 31, 2018. Self-administered questionnaires based on the objectives of the study were given out to participants to complete after their consent was sought.

2.2. Study Area. The research work was carried out in the UHAS. It is located at Ho in the Volta region of Ghana on $6.5739^{\circ} \mathrm{N}, 0.4410^{\circ} \mathrm{E}$. The university happens to be one of the newest and youngest public universities in Ghana mandated to train health care personnel. Currently, it operates under six schools, namely School of Medicine, School of Nursing and Midwifery, School of Public Health, School of Basic and Biomedical Sciences, School of Pharmacy, and School of Allied Health Sciences. The School of Allied Health Sciences is situated on the premises of the Volta Regional Hospital, now Ho Teaching Hospital, a leading referral hospital in the region and a centre for the training of Allied Health Professionals. The School of Allied Health Sciences comprises of six departments including Department of Medical Laboratory Sciences (DMLS) where the study was carried out. The department offers both regular and sandwich/modular programmes for the award of a Bachelor's degree.

2.3. Sampling Procedure. Of 241 students, a total of 178 participants were enrolled for the study based on Cochran's formula, $Z^{2 *} p(1-p) / d^{2}$, and prevalence of occupational exposure to $\mathrm{BBF}$ in a previous study among nursing students on internship [20]. A sample size of 178 was calculated using a prevalence $(p)$ of $88.6 \%, 5 \%$ margin error (d), 95\% confidence interval $(Z)$ given as 1.96 and $15 \%$ attrition rate to cater for non-response. This total sample size was distributed depending on the class size of the year groups, and the simple random sampling method was then used to recruit participants from each year into the study. A 100\% response rate was achieved since all the students who were recruited consented and partook in the study.

2.3.1. Inclusion Criteria. Continuing students who were in their $2^{\text {nd }}, 3^{\text {rd }}$, or $4^{\text {th }}$ year and had completed the annual compulsory vocational training programme held within the period of June to August 2017 were eligible for the study.

2.3.2. Exclusion Criteria. Fresh students who were in their $1^{\text {st }}$ year and had not completed the annual compulsory vocational training programme held within the interval of June-August 2017 were ineligible and were not recruited for the study. 
2.4. Data Collection Technique. Self-administered closedended structured questionnaires were used to gather relevant data on the study objectives and research questions. This information included sociodemographic characteristics, standard precautionary measures, HBV vaccination status, as well as routes of exposure to BBF based on earlier investigations $[18,20,21]$. The questionnaires were completed by eligible participants and collected before and after lecture periods within the two-month duration of data collection.

2.5. Data Processing and Analysis. Data from the completed questionnaires were then entered into Microsoft Excel and imported into Stata, version 15 (64 bit), for editing and analysis. Descriptive statistics such as frequency and proportion were used to analyse the demographic factors, risk factors, and exposure to BBF. Chi-square test and Fisher's exact test were used to test for the association between risk factors and exposure to BBF, based on a statistical significance at $95 \%$ confidence interval. Crude odds ratios, adjusted odds ratios, 95\% confidence intervals, and pvalues were calculated using bivariate and multiple logistic regression to describe the relationship between exposure to $\mathrm{BBF}$ and their associated risk factors. The variables with an observed association of $p<0.05$ were noted and considered significant.

2.5.1. Categorization of Exposure Status. The categorization of participants' exposure status was based on incidence of four routes of exposure to BBF during the vocational internship period held between June and August 2017. These were needlestick, sharp injuries, splash, and torn gloves. Participants who were not exposed to blood in any of the four routes of exposure during the last vocational training programmes were classified as nonexposed, whereas others who experienced at least one of the ways of exposure were grouped as exposed.

2.6. Ethical Consideration. Approval of the study protocol was obtained from the Ethical Review Committee of the Ghana Health Service (GHS-ERC) before commencement of the study. Permission was sought from the Department of Medical Laboratory Sciences (DMLS) of the UHAS before the data collection. Study participants were briefed about the purpose, risk, and benefits of the study before appending their signature on the consent form to take part in the survey.

\section{Results}

3.1. Sociodemographic Characteristics of Study Participants. A total of 178 MLSS were enrolled into the study. As depicted, $139(78.1 \%)$ of these participants were males, and the majority 118 (66.3\%) were 20-24 years of age. Most of the students, 166 (93.3\%), were Christians. Most of the participants, 165 (92.7\%), were not married. With respect to residence, $143(80.3 \%)$ lived outside campus. In addition, more than half, 91 (51.1\%), of students were in their $2^{\text {nd }}$ year, whereas $64(36.0 \%)$ and $23(12.9 \%)$ were in their $3^{\text {rd }}$ and $4^{\text {th }}$ year, respectively. A considerable number of students, 155 (87.1\%), had no working experience before university education. During the time of the study, a majority of students, $105(59.0 \%)$, had embarked on vocational training for less than two months (Table 1).

3.2. Prevalence of Exposure to BBF according to Sociodemographic Characteristics. A higher prevalence (51.3\%) of exposure to BBF was found among students who were females. Also, a greater prevalence $(53.9 \%)$ was reported among students who were married, whereas $51.1 \%$ was reported among students who did not stay on campus. In addition, the age range " $20-24$, " $4^{\text {th }}$ year group, and students who did 2-4 months' vocational training recorded the highest exposure to $\mathrm{BBF}$ as $54.2 \%, 56.5 \%$, and $61.5 \%$, respectively. Also, students who had worked before university education had a higher exposure prevalence of $60.9 \%$ compared with those who never worked (Table 1).

3.3. Exposure Status of Study Participants. A little more than half, $50.6 \%$, of participants were exposed to BBF while undergoing the 2017 vocational training programme (Figure 1).

3.4. Occupational Exposure to BBF among Study Participants. Of the participants surveyed, 57 (32.0\%) experienced torn gloves, 38 (21.3\%) experienced splash of BBF, 25 (14.0\%) experienced needlestick, and 14 (7.9\%) had some form of sharp-related injuries (Figure 2).

3.5. Association between Risk Factors and Exposure to BBF Status. The only risk factor that showed a significant association with exposure to BBF status was the sufficient PPE to students on vocational internship programmes (Pearson $\operatorname{chi}^{2}=5.3$, pvalue $\left.=0.021\right)($ Table 1$)$.

3.6. Bivariate and Multiple Logistic Regression Analysis on Exposure to BBF. Students who had work experience in a medical laboratory before pursuing university education had increased the odds of exposure to BBF by more than 7 times $(\mathrm{AOR}=7.37, \quad 95 \% \quad \mathrm{CI}=1.22-44.43$, pvalue $=0.029)$ compared with those who had no work experience. On the contrary, sufficient PPE to students decreased the odds of exposure to BBF by almost $59 \%$ $(\mathrm{AOR}=0.41,95 \% \mathrm{CI}=0.20-0.88$, pvalue $=0.023) \mathrm{com}-$ pared with students who did not have access to sufficient PPE (Table 2).

\section{Discussion}

MLSS and all other HCW inevitably get exposed to BBF of patients through needlestick, sharp injuries, and mucocutaneous contamination [22]. The extent of exposure of these students is even heightened due to their inexperience during their annual compulsory vocational training programmes 
TABLE 1: Chi-square analysis of factors influencing exposure to BBF.

\begin{tabular}{|c|c|c|c|c|c|}
\hline Variable & Frequency, $n=178(100.0 \%)$ & No exposure, $n=88(49.4 \%)$ & Exposure, $n=90(50.6 \%)$ & Chi-square & $p$ value \\
\hline $\begin{array}{l}\text { Gender } \\
\text { Female } \\
\text { Male }\end{array}$ & $\begin{array}{c}39(21.9) \\
139(78.1) \\
\end{array}$ & $\begin{array}{l}19(48.7) \\
69(49.6)\end{array}$ & $\begin{array}{l}20(51.3) \\
70(50.4)\end{array}$ & 0.0 & 0.919 \\
\hline $\begin{array}{l}\text { Age in years } \\
15-19 \\
20-24 \\
25-29 \\
>29\end{array}$ & $\begin{array}{c}14(7.9) \\
118(66.3) \\
31(17.4) \\
15(8.4) \\
\end{array}$ & $\begin{array}{c}9(64.3) \\
54(45.8) \\
18(58.1) \\
7(46.7) \\
\end{array}$ & $\begin{array}{c}5(35.7) \\
64(54.2) \\
13(41.9) \\
8(53.3) \\
\end{array}$ & 2.8 & 0.417 \\
\hline $\begin{array}{l}\text { Work history } \\
\text { Never worked } \\
\text { Ever worked }\end{array}$ & $\begin{array}{c}155(87.1) \\
23(12.9)\end{array}$ & $\begin{array}{c}79(51.0) \\
9(39.1) \\
\end{array}$ & $\begin{array}{l}76(49.0) \\
14(60.9) \\
\end{array}$ & 1.2 & 0.289 \\
\hline $\begin{array}{l}\text { Year group } \\
2^{\text {nd }} \text { year } \\
3^{\text {rd }} \text { year } \\
4^{\text {th }} \text { year }\end{array}$ & $\begin{array}{l}91(51.1) \\
64(36.0) \\
23(12.9) \\
\end{array}$ & $\begin{array}{l}47(51.7) \\
31(48.4) \\
10(43.5) \\
\end{array}$ & $\begin{array}{l}44(48.3) \\
33(51.6) \\
13(56.5) \\
\end{array}$ & 0.5 & 0.767 \\
\hline $\begin{array}{l}\text { Vocational } \\
<2 \text { months } \\
3-4 \text { months } \\
5-6 \text { months } \\
>6 \text { months }\end{array}$ & $\begin{array}{c}105(59.0) \\
52(29.2) \\
15(8.4) \\
6(3.4)\end{array}$ & $\begin{array}{c}57(54.3) \\
20(38.5) \\
8(53.3) \\
3(50.0)\end{array}$ & $\begin{array}{l}48(45.7) \\
32(61.5) \\
7(46.7) \\
3(50.0)\end{array}$ & 3.6 & $0.293^{a}$ \\
\hline $\begin{array}{l}\text { Use of gloves } \\
\text { No } \\
\text { Yes }\end{array}$ & $\begin{array}{c}1(0.6) \\
177(99.4)\end{array}$ & $\begin{array}{c}0(0.0) \\
88(49.7) \\
\end{array}$ & $\begin{array}{l}1(100.0) \\
89(50.3) \\
\end{array}$ & 1.0 & $0.506^{a}$ \\
\hline $\begin{array}{l}\text { Disinfection } \\
\text { No } \\
\text { Yes }\end{array}$ & $\begin{array}{c}2(1.1) \\
176(98.9) \\
\end{array}$ & $\begin{array}{c}1(50.0) \\
87(49.4) \\
\end{array}$ & $\begin{array}{c}1(50.0) \\
89(50.6) \\
\end{array}$ & 0.0 & $1.000^{a}$ \\
\hline $\begin{array}{l}\text { Training on ID } \\
\text { No } \\
\text { Yes }\end{array}$ & $\begin{array}{l}85(51.98) \\
93(52.25) \\
\end{array}$ & $\begin{array}{l}39(45.9) \\
49(52.7) \\
\end{array}$ & $\begin{array}{l}46(54.1) \\
44(47.3) \\
\end{array}$ & 0.8 & 0.364 \\
\hline $\begin{array}{l}\text { Vaccinated } \\
\text { No } \\
\text { Yes }\end{array}$ & $\begin{array}{c}101(56.7) \\
77(43.3) \\
\end{array}$ & $\begin{array}{l}51(50.5) \\
37(48.1) \\
\end{array}$ & $\begin{array}{l}50(49.5) \\
40(51.9)\end{array}$ & 0.1 & 0.764 \\
\hline $\begin{array}{l}\text { Sufficient PPE } \\
\text { No } \\
\text { Yes }\end{array}$ & $\begin{array}{c}46(25.8) \\
132(74.2)\end{array}$ & $\begin{array}{l}16(34.8) \\
72(54.5)\end{array}$ & $\begin{array}{l}30(65.2) \\
60(45.5)\end{array}$ & 5.3 & $0.021^{*}$ \\
\hline
\end{tabular}

All pvalues were calculated using the chi-square test except the ones denoted by ${ }^{a}$ which were using Fisher's exact test. $p$ values denoted by ${ }^{*}$ are significant at $p<0.05$.

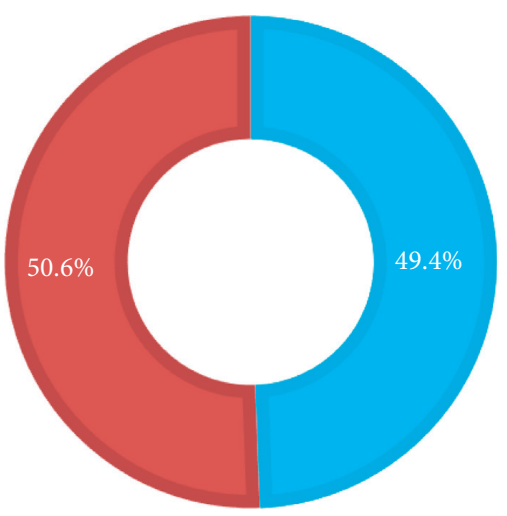

No exposure

Exposure

FIGURE 1: Exposure status of study participants.

[10]. As a result, it was imperative to study and discuss the possible risk factors of exposure to BBF to avert impending exposure in future vocational internships.

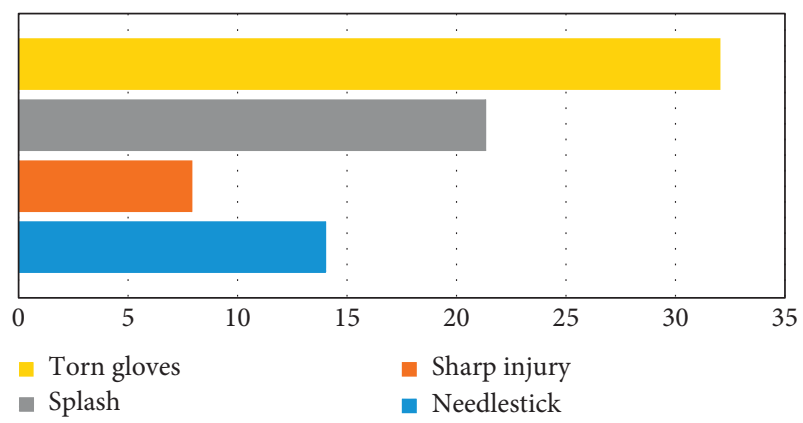

FIgURE 2: Routes of occupational exposure to BBF among participants.

The present study depicted that the majority $(87.1 \%)$ of participants had no work experience prior to the annual vocational internship programme held in 2017. This finding was in line with a study among dental and nursing students where the majority $(83.6 \%)$ had no or less than 6 months experience [20]. Although the study revealed that work 
TABLE 2: Bivariate and multivariate logistic regression analysis of factors influencing exposure to BBF.

\begin{tabular}{|c|c|c|c|c|c|c|c|}
\hline Variable & $\begin{array}{c}\text { Frequency } \\
n=178(100.0 \%)\end{array}$ & $\begin{array}{c}\text { No exposure } \\
n=88(49.4 \%)\end{array}$ & $\begin{array}{c}\text { Exposure } \\
n=90(50.6 \%)\end{array}$ & pvalue & $\begin{array}{c}\text { COR } \\
\text { OR }(95 \% \mathrm{CI}) \\
\end{array}$ & $p$ value & $\begin{array}{c}\text { AOR } \\
\text { OR }(95 \% \mathrm{CI})\end{array}$ \\
\hline $\begin{array}{l}\text { Gender } \\
\text { Female } \\
\text { Male }\end{array}$ & $\begin{array}{c}39(21.9) \\
139(78.1)\end{array}$ & $\begin{array}{l}19(48.7) \\
69(49.6) \\
\end{array}$ & $\begin{array}{l}20(51.3) \\
70(50.4) \\
\end{array}$ & 0.919 & $\begin{array}{c}1.00 \\
0.96(0.47-1.96) \\
\end{array}$ & 0.779 & $\begin{array}{c}1.00 \\
1.12(0.49-2.56) \\
\end{array}$ \\
\hline $\begin{array}{l}\text { Age in years } \\
15-19 \\
20-24 \\
25-29 \\
>29\end{array}$ & $\begin{array}{c}14(7.9) \\
118(66.3) \\
31(17.4) \\
15(8.4) \\
\end{array}$ & $\begin{array}{c}9(64.3) \\
54(45.8) \\
18(58.1) \\
7(46.7) \\
\end{array}$ & $\begin{array}{l}5(35.7) \\
64(54.2) \\
13(41.9) \\
8(53.3) \\
\end{array}$ & $\begin{array}{l}0.197 \\
0.694 \\
0.343 \\
\end{array}$ & $\begin{array}{c}1.00 \\
2.13(0.67-6.75) \\
1.30(0.35-4.80) \\
2.06(0.46-9.14) \\
\end{array}$ & $\begin{array}{l}0.528 \\
0.479 \\
0.294 \\
\end{array}$ & $\begin{array}{c}1.00 \\
1.52(0.41-5.58) \\
0.55(0.11-2.83) \\
0.27(0.02-3.12) \\
\end{array}$ \\
\hline $\begin{array}{l}\text { Year group } \\
2^{\text {nd }} \text { year } \\
3^{\text {rd }} \text { year } \\
4^{\text {th }} \text { year }\end{array}$ & $\begin{array}{l}91(51.1) \\
64(36.0) \\
23(12.9) \\
\end{array}$ & $\begin{array}{l}47(51.7) \\
31(48.4) \\
10(43.5) \\
\end{array}$ & $\begin{array}{l}44(48.3) \\
33(51.6) \\
13(56.5) \\
\end{array}$ & $\begin{array}{l}0.694 \\
0.485 \\
\end{array}$ & $\begin{array}{c}1.00 \\
1.14(0.60-2.16) \\
1.39(0.55-3.49)\end{array}$ & $\begin{array}{l}0.392 \\
0.292 \\
\end{array}$ & $\begin{array}{c}1.00 \\
0.65(0.24-1.74) \\
2.10(0.53-8.40) \\
\end{array}$ \\
\hline $\begin{array}{l}\text { Work history } \\
\text { Never worked } \\
\text { Ever worked } \\
\end{array}$ & $\begin{array}{c}155(87.1) \\
23(12.9) \\
\end{array}$ & $\begin{array}{c}79(51.0) \\
9(39.1) \\
\end{array}$ & $\begin{array}{l}76(49.0) \\
14(60.9) \\
\end{array}$ & 0.292 & $\begin{array}{c}1.00 \\
1.62(0.66-3.96) \\
\end{array}$ & $0.029^{*}$ & $\begin{array}{c}1.00 \\
7.37(1.22-44.43) \\
\end{array}$ \\
\hline $\begin{array}{l}\text { Vocational } \\
<2 \text { months } \\
3-4 \text { months } \\
5-6 \text { months } \\
>6 \text { months }\end{array}$ & $\begin{array}{c}105(59.0) \\
52(29.2) \\
15(8.4) \\
6(3.4) \\
\end{array}$ & $\begin{array}{l}57(54.3) \\
20(38.5) \\
8(53.3) \\
3(50.0)\end{array}$ & $\begin{array}{l}48(45.7) \\
32(61.5) \\
7(46.7) \\
3(50.0)\end{array}$ & $\begin{array}{l}0.063 \\
0.945 \\
0.838 \\
\end{array}$ & $\begin{array}{c}1.00 \\
1.90(0.96-3.74) \\
1.03(0.35-3.07) \\
1.18(0.23-6.16) \\
\end{array}$ & $\begin{array}{l}0.073 \\
0.303 \\
0.945 \\
\end{array}$ & $\begin{array}{c}1.00 \\
2.45(0.92-6.58) \\
0.44(0.10-2.06) \\
1.08(0.14-8.45) \\
\end{array}$ \\
\hline $\begin{array}{l}\text { Vaccinated } \\
\text { No } \\
\text { Yes }\end{array}$ & $\begin{array}{l}101(56.74) \\
77(43.26)\end{array}$ & $\begin{array}{l}51(50.5) \\
37(48.1) \\
\end{array}$ & $\begin{array}{l}50(49.5) \\
40(51.9) \\
\end{array}$ & 0.747 & $\begin{array}{c}1.00 \\
1.10(0.60-2.00)\end{array}$ & 0.932 & $\begin{array}{c}1.00 \\
1.02(0.53-2.00) \\
\end{array}$ \\
\hline $\begin{array}{l}\text { Training on ID } \\
\text { No } \\
\text { Yes }\end{array}$ & $\begin{array}{l}85(51.98) \\
93(52.25)\end{array}$ & $\begin{array}{l}39(45.9) \\
49(52.7)\end{array}$ & $\begin{array}{l}46(54.1) \\
44(47.3)\end{array}$ & 0.365 & $\begin{array}{c}1.00 \\
0.76(0.42-1.37) \\
\end{array}$ & 0.689 & $\begin{array}{c}1.00 \\
0.88(0.46-1.68) \\
\end{array}$ \\
\hline $\begin{array}{l}\text { Sufficient PPE } \\
\text { No } \\
\text { Yes }\end{array}$ & $\begin{array}{c}46(25.8) \\
132(74.2)\end{array}$ & $\begin{array}{l}16(34.8) \\
72(54.5)\end{array}$ & $\begin{array}{l}30(65.2) \\
60(45.5)\end{array}$ & $0.02^{*}$ & $\begin{array}{c}1.00 \\
0.44(0.22-0.89)\end{array}$ & $0.023^{*}$ & $\begin{array}{c}1.00 \\
0.41(0.20-0.88)\end{array}$ \\
\hline
\end{tabular}

$p$ values denoted by ${ }^{*}$ are significant at $<0.05$.

history was not significantly associated with exposure status, inadequate experience has been suggested as an increased risk of occupational injury among students carrying out invasive medical procedures [20].

Our study found that only $74.2 \%$ of participants had access to sufficient PPE. This result was in contrast to the study by Yasin et al. [17] in Ethiopia where $77.0 \%$ of HCW complained of not having adequate PPE over the past one year. The difference in results may be due to variations in the strength of health care system, supply chain, and finances of health care facilities. The significant association observed between sufficient PPE and exposure status solidifies the statement made by the WHO amidst the coronavirus disease 19 (COVID-19) pandemic that HCW rely solely on PPE for protection against infection from patients [23].

Again, it is evident in our study that $56.4 \%$ of MLSS had received vaccination against hepatitis $B$ virus infection. This result was not in coherent with a study in Kenya among HCW that revealed $40.0 \%$ hepatitis B vaccination coverage [24]. However, our finding was comparable with a study that predicted $55.3 \%$ hepatitis B vaccination status among HCW [17]. Although our study showed a little over $50 \%$ hepatitis B vaccination coverage, it does not meet the WHO-recommended coverage of $100 \%$. In the context of this study, the possible causes of low coverage of hepatitis $B$ vaccination may comprise the two major factors-high cost of vaccine and lack of policy to make hepatitis B vaccination compulsory for health care students.

The current study showed that $52.3 \%$ of study participants had received training on infectious diseases and prevention that was organized by their host health care facilities prior to the start of their vocational training programme. This result was not consistent with a study conducted by [25] that found $48.8 \%$ of participants had received training on infectious diseases and prevention. The dissimilarity in results may be due to the priority management of health care facilities places on training focused on infectious diseases and prevention and in some cases the lack of funds to organize continuous training programmes for HCW.

Further, our results showed that almost all (99.4\%) of participants used gloves one way or the other in their line of work, yet, of all the routes of exposure, torn gloves was experienced by most students with a prevalence of $32.0 \%$. This result was similar to a study where participants experienced $28.9 \%$ of glove breakage [26]. Glove breakage can be associated with sudden movement of patients during sample collection and waste disposal [27]. Moreover, the low quality of gloves is also known to contribute to this situation. This even confirms the reason why most HCW practice double 
gloving when performing a high risk procedure. Additionally, torn gloves is mostly experienced in the process of wearing and removing, and the degree of exposure is worse when removing it after a procedure has been done. This certainly calls for education on wearing and removal of gloves among HCW especially health care students.

Our current study predicted that $50.6 \%$ of participants were exposed to BBF; this result is similar to studies conducted in Durban, Iran, and Egypt where 55.0\%, 53.4\%, and $51.3 \%$ of medical interns, health care professionals, and dental students, respectively, were exposed to BBF in the past one year $[20,28,29]$. Nevertheless, the finding of this study was lower than BBF exposure levels, $88.6 \%$ and $75.6 \%$ predicted among nursing students in some studies $[18,20]$. The differences in findings may be due to lack of training on infectious diseases, its control and exposure, duration of internship/vocational training programmes, nonadherence to safety precautionary measures, insufficient PPE and supporting facilities, and duration of exposure to BBF $[17,20]$.

With reference to our findings, work experience increased the exposure to BBF among students who worked before pursing university education more than 7 times $(\mathrm{AOR}=7.37,95 \% \mathrm{CI}=1.22-44.43$, pvalue $=0.029) \quad$ compared with those who had no work experience. The evidence from our study was similar to a study among HCW where participants who had more than 10 years' experience had over 4 times $(\mathrm{AOR}=4.13,95 \% \mathrm{CI}=1.56-10.91)$ risk of exposure compared with those who had less than two years' experience [30]. In our Ghanaian health settings, it is not common to find experienced HCW who adhere to all precautionary measures. However, this attitude of experienced HCW may be influenced by the lack of PPE in our health facilities and forgetfulness that usually comes into play when handling medical emergencies.

Finally, our study revealed that for participants who had sufficient PPE, the odds of exposure to BBF reduced by almost $\quad 59 \% \quad(\mathrm{AOR}=0.41, \quad 95 \% \quad \mathrm{CI}=0.20-0.88$, pvalue $=0.023)$ compared with students who did not had inadequate PPE at their disposal. This discovery is coherent to the study by Yenesew and Fekadu in which shortage of PPE increased the odds of exposure to BBF by approximately 2 times $(\mathrm{COR}=1.75,95 \% \mathrm{CI}=1.09-2.79)$ compared with those who did not experience shortage of PPE in their health facility [27]. The use of PPE from this study and other studies have proven to be the surest way of preventing exposure to $\mathrm{BBF}$ and its availability counts in the prevention of these exposures.

\section{Limitations of the Study}

Although students were asked to remember the exposure they encountered during their last vocational internship programme that was held between June and August 2017, approximately eight (8) months ago, there is still possibility of recall bias among these students and this might have contributed to distortion in the prevalence of exposure to BBF. As well, generalization of the results of this study is limited since participants were drawn from only one institution. It is probable that a large sample size of participants from different institutions may have presented a similar but different picture.

\section{Conclusion}

The study revealed that $50.6 \%$ (95\% CI: $43.0 \%-58.1 \%$ ) of MLSS experienced at least one exposure to BBF during the vocational internship. Work history before pursuing university education and sufficient PPE were the most significantly associated risk factors of exposure to BBF. Torn gloves was the most prevalent route of exposure to $\mathrm{BBF}$ among needlestick, splashes of BBF, and sharp-related injuries.
Abbreviations
AOR: Adjusted odds ratio
BBF: Blood and body fluids
CI: Confidence interval
COR: Crude odds ratio
HCW: Heath care workers
MLSS: Medical laboratory science students
PPE: Personal protective equipment
UHAS: University of Health and Allied Sciences
WHO: World Health Organization

\section{Data Availability}

Research data will be made available upon request.

\section{Additional Points}

Definition of Operational Terms. Needlestick: wounds or injuries caused by needles that accidentally puncture the skin during health care medical procedures. Sharp injury: exposure events that result when medical sharps such as scalpels, broken glass, and broken capillary tube penetrate the skin.

\section{Conflicts of Interest}

The authors declare no conflicts of interest.

\section{Authors' Contributions}

Philip Apraku Tawiah designed the study, searched literature, wrote the protocol, and collected data. Albert AbakaYawson, Emmanuel Sintim Effah, and Philip Apraku Tawiah managed the preliminary statistical analysis and wrote the first draft of the manuscript. Kwabena Oppong, Kingsley Arhin-Wiredu, and Philip Apraku Tawiah managed the final statistical analysis of the study and wrote the final manuscript. All authors read and approved the final manuscript.

\section{Acknowledgments}

The authors express their profound gratitude to the entire management of the Department of Medical Laboratory 
Sciences, University of Health Allied Sciences, Ho, Ghana, for their backing in making this study successful.

\section{References}

[1] K. A. Sepkowitz, "Occupationally acquired infections in health care workers," Annuals Of International Medicine, vol. 125, no. 11, pp. 917-928, 2011, American College of Physicians.

[2] C. Rapparini, "Occupational HIV infection among health care workers exposed to blood and body fluids in Brazil," American Journal of Infection Control, vol. 34, no. 4, pp. 237-240, 2006.

[3] A. Tarantola, D. Abiteboul, and A. Rachline, "Infection risks following accidental exposure to blood or body fluids in health care workers: a review of pathogens transmitted in published cases," American Journal of Infection Control, vol. 34, no. 6, pp. 367-375, 2006.

[4] E. P.-Ü. Rapiti and Y. A Hutin, Sharp Injuries. Assessing the Burden of Disease from Sharps Injuries to Health-Care Workers at National and Local Levels, World Health Organization, Geneva, Switzerland, 2005.

[5] Control for Disease Control and Prevention and Division of Healthcare Quality Promotion, Surveillance of Healthcare Personnel with HIV/AIDS, as of December 2001, CDC, Washington, DC, USA, 2003.

[6] Y. Belyhun, M. Maier, A. Mulu, E. Diro, and U. G. Liebert, "Hepatitis viruses in Ethiopia: a systematic review and metaanalysis," BMC Infectious Diseases, vol. 16, no. 1, p. 761, 2016.

[7] Ghana Health Service, Ghana Health Service 2016 Annual Report, Ghana Health Service, Accra, Ghana, 2017.

[8] M. Nguyen, S. Paton, and J. Koch, "Update-surveillance of health care workers exposed to blood, body fluids and bloodborne pathogens in Canadian hospital settings: 1 April, 2000, to 31 March, 2002," Canada Communicable Disease Report, vol. 29, no. 24, 2003.

[9] M. Falagas, I. Karydis, and I. Kostogiannou, "Percutaneous exposure incidents of the health care personnel in a newly founded tertiary hospital: a prospective study," PLoS One, vol. 2, no. 2, p. 194, 2007.

[10] M. Askarian, L. Malekmakan, M.-L. McLaws, N. Zare, and J. M. M. Patterson, "Prevalence of needlestick injuries among medical students at a university in Iran," Infection Control \& Hospital Epidemiology, vol. 27, no. 1, pp. 99-101, 2006.

[11] S. K. F. Elliott, A. Keeton, and A. Holt, "Medical students' knowledge of sharps injuries," Journal of Hospital Infection, vol. 60, no. 4, pp. 374-377, 2005.

[12] M. Saia, F. Hofmann, and J. Sharman, "Needle-stick injuries: incidence and cost in the United States, United Kingdom, Germany, France, Italy and Spain," BioMed Research International, vol. 1, pp. 41-49, 2010.

[13] W. Tosini, C. Ciotti, F. Goyer et al., "Needlestick injury rates according to different types of safety-engineered devices: results of a French multicenter study," Infection Control \& Hospital Epidemiology, vol. 31, no. 4, pp. 402-407, 2010.

[14] M. Kakizaki, N. Ikeda, and M. N. Ali, "Needlestick and sharps injuries among healthcare workers at public tertiary hospitals in an urban community in Mongolia," BMC Res Notes, vol. 4, no. 1, p. 184, 2011.

[15] F. Shiva, A. Sanaei, and A. Shamshiri, "Survey of needle-stick injuries in paediatric health personnel of 5 university hospitals in Tehran," Journal of Pakistan Medical Association, vol. 61, no. 2, pp. 127-131, 2011.
[16] L. Markovic-Denic, N. Maksimovic, V. Marusic, J. Vucicevic, I. Ostric, and D. Djuric, "Occupational exposure to blood and body fluids among health-care workers in Serbia," Medical Principles and Practice, vol. 24, no. 1, pp. 36-41, 2015.

[17] J. Yasin, R. Fisseha, F. Mekonnen, and K. Yirdaw, "Occupational exposure to blood and body fluids and associated factors among health care workers at the university of Gondar hospital, Northwest Ethiopia," Environmental Health and Preventive Medicine, vol. 24, no. 1, pp. 1-9, 2019.

[18] H. Chon, H. Jeong-hwan, and H. B. Lee, "Nursing students' exposure to blood and body fluids in clinical practicum nursing students' exposure to blood and body fluids in clinical practicum," Journal of East-West Nursing Research, vol. 16, no. 1, pp. 70-75, 2010.

[19] S. Shaghaghian, A. Golkari, S. Pardis, and A. Rezayi, "Occupational exposure of shiraz dental students to patients' blood and body fluid," Journal of Dentistry, vol. 16, no. 3, pp. 206-213, 2015.

[20] A. A. El-Houfey, S. A. Sharkawey, and A. K. Hassan, "Occupational exposure to blood and body fluids among nursing and dental students at internship year in Assiut City," Journal of American Science, vol. 9, no. 5, pp. 466-475, 2013.

[21] V. Apetorgbor, "Occupational exposure to blood and body fluids among health workers: the case of Shai-Osudoku district hospital," University of Ghana, Accra, Ghana, MPH, 2018.

[22] E. Davanzo, C. Frasson, M. Morandin, and A. Trevisan, "Occupational blood and body fluid exposure of university health care workers," American Journal of Infection Control, vol. 36, no. 19, pp. 753-756, 2008.

[23] World Health Organisation, World Health Statistics, WHO, Geneva, Switzerland, 2010.

[24] E. Mbaisi, P. Wanzala, and J. Omolo, "Prevalence and factors associated with percutaneous injuries and splash exposures among health-care workers in a provincial hospital, Kenya, 2010," Pan African Medical Journal, vol. 14, no. 1, 2013.

[25] D. Ogoina, K. Pomde, B. Adetunji, G. Chima, C. Isichei, and S. Gidado, "Prevalence and determinants of occupational exposure to blood and body fluids among health workers in two tertiary hospitals in Nigeria," African Journal of Infectious Diseases, vol. 8, no. 2, pp. 50-54, 2014.

[26] M. Tadesse, "Occupational exposure to blood and body fluids among health care workers in wolaita zone, southern Ethiopia," Developing Countries Studies, vol. 6, no. 7, pp. 70-77, 2016.

[27] F. A. Tesfay and T. D. Habtewold, "Assessment of prevalence and determinants of occupational exposure to HIV infection among healthcare workers in selected health institutions in Debre Berhan town, north Shoa zone, Amhara region, Ethiopia, 2014," Aids Research and Treatment, vol. 2014, Article ID 731848, 11 pages, 2014.

[28] H. Karani, S. Rangiah, and A. Ross, "Occupational exposure to blood-borne or body fluid pathogens among medical interns at Addington hospital, Durban," South African Family Practice, vol. 53, no. 5, pp. 2003-2007, 2011.

[29] S. Shokuhi, L. Gachkar, I Alavi-Darazam, P. Yuhanaee, and M. Sajadi, "Occupational exposure to blood and body fluids among health care workers in teaching hospitals in Tehran, Iran," Iranian Red Crescent Medical Journal, vol. 14, no. 7, pp. $402-407,2012$.

[30] M. A. Yenesew and G. A. Fekadu, "Occupational exposure to blood and body fluids among health care professionals in Bahir Dar Town, Northwest Ethiopia," Safety and Health at Work, vol. 5, no. 1, pp. 17-22, 2014. 